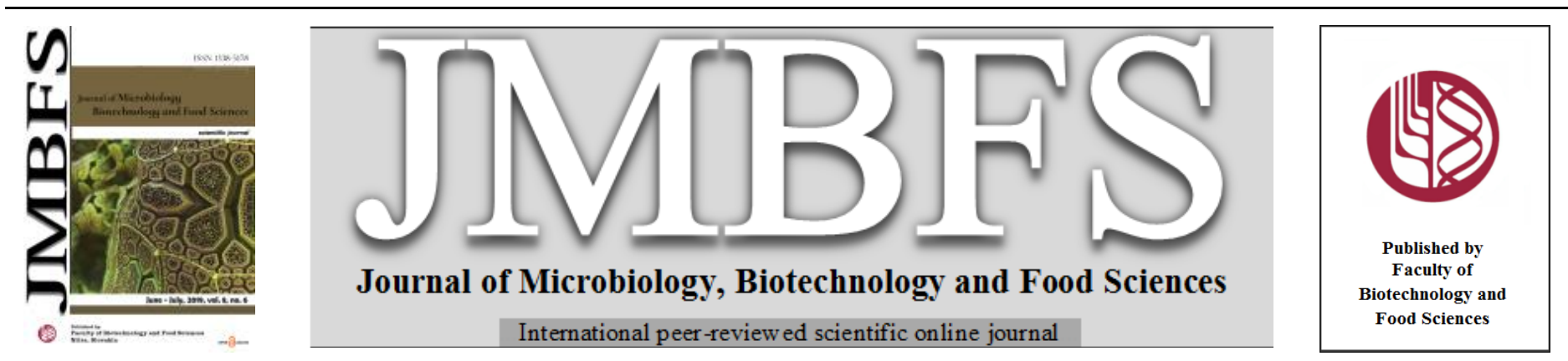

\title{
CLONING OF DNA POLYMERASE-1 GENE FROM THERMOPHILIC Bacillus licheniformis STRAIN NWMF1 INTO AN E.coli EXPRESSION SYSTEM
}

\author{
Janith Manohara Bandara Wanigasekara Wanigasekara Mudiyanselage, Navoda Palpola, Wijepurage Sandhya Sulochana \\ Wijesundera, Deepal Mathew, Sharmila Manoji Tarita Jayasena*
}

Address(es):
Department of Biochemistry and Molecular Biology, Faculty of Medicine University of Colombo.

*Corresponding author: sharmila@bmb.cmb.ac.lk

doi: 10.15414/jmbfs.2019.8.6.1317-1319

\section{ARTICLE INFO}

Received 14. 10. 2018

Revised 4. 2. 2019

Accepted 5. 2. 2019

Published 1. 6. 2019

Regular article open $\mathcal{C A C C E S S}$

\begin{abstract}
DNA polymerase, catalyze template directed synthesis of DNA from nucleotide triphosphate. Thermostable DNA polymerase-I (DNAP1) has been a common reagent in molecular biology because of its use in DNA amplification and DNA sequencing by PCR. DNAP-1 produced in moderate thermophiles such as Bacillus species may not be suitable for PCR, However, moderately thermophilic DNAP-1 from Bacillus has been used in molecular biology techniques such as loop mediated isothermal amplification. It is a low cost alternative to detect certain infectious diseases such as tuberculosis, malaria and can be applied in low/middle income countries. The objective of the study was isolation and cloning of DNAP-1 gene from native thermophilic bacterium, Bacillus licheniformis strain NWMF1 and over-expression by using expression host E. coli BL21(DE3)pLysS. A gram +ve endospore forming thermophilic bacterium was isolated from soil near the hot-water springs at Polonnaruwa, Sri Lanka. The identification of Bacillus licheniformis strain NWMF1 was carried out using morphological tests and 16s r.RNA gene sequence analysis. Initially the gene was cloned into pGEMT-easy vector and transformed into $E$. coli JM109 followed by sequence confirmation and protein blast analysis by NCBI. Thereafter the DNAP-1 gene re-cloned into PET28a+ vector and transformed into E. coli BL21(DE3)pLysS expression host. Recombinant $E$. coli clones were confirmed by colony PCR. Sequence analysis confirmed the presence of the complete gene (2640bp) including start and stop codons. The complete protein sequence consists 879 amino acids. SDS-PAGE and analysis by EXPASyProtParam indicated the molecular weight of DNAP-1 as $\sim 92 \mathrm{kDa}$. Polymerase activity of His-tag purified DNAP-1 was demonstrated by PCR methodology.
\end{abstract}

Keywords: Bacillus licheniformis, Cloning, DNA Polymerase-1, Expression

\section{INTRODUCTION}

The thermostable DNA polymerases, like other DNA polymerases (E.C 2.7.7.7), catalyze template directed synthesis of DNA from nucleotide triphosphates. Commercial preparations of DNA polymerases have a variety of applications in DNA manipulations in vitro, such as sequencing, labeling, cDNA synthesis etc. (Ishino and Ishino, 2014). These enzymes are commercially produced in convenient, high-yielding mesophilic hosts such as E. coli, by the use of recombinant DNA technology. DNA polymerases such as Taq polymerase which have an optimal temperature of $\sim 80^{\circ} \mathrm{C}$ are extensively used in PCR. DNA polymerases from moderate thermophiles have uses in molecular diagnostic techniques such as Loop Mediated Isothermal Amplification (LAMP). It is a low cost alternative to PCR that can be applied in low and middle-income countries for screening /diagnosis of infectious diseases (Mori et al., 2013). LAMP has been observed to be less sensitive to inhibitors in clinical samples when compared to PCR and successful detection of pathogens from minimally processed samples such as heat-treated blood has been reported (Curtis $\boldsymbol{e t}$ al., 2008: Sattabongkot et al., 2014). Further, they can be applied for in vitro DNA manipulation techniques in the molecular biology, where a higher temperature reaction is more suitable. The objectives of this project were to clone and overexpress the DNA polymerase I (DNAP-1) gene from a thermophilic bacterium, with a view to subsequent scale up.

\section{MATERIALS AND METHODS}

The Bacillus licheniformis strain NWMF1 was cultured in LB medium at $55^{\circ} \mathrm{C}$ with constant shaking. Plasmid DNA isolation was by alkaline SDS method (Sambrook et al., 2012). DNA fragments were purified from agarose gels using Wizard SV gel purification system (Promega USA). All DNA ligations were carried out using Liga-Fast Rapid DNA Ligation System according to manufacturers' protocol. Sanger sequencing was outsourced (Macrogen, Korea). DNA and translated amino acid sequences were analyzed by nucleotide and protein BLAST tools using online sequence databases available at NCBI.

\section{Isolation and identification of thermophilic bacteria}

The thermophilic bacterium was isolated from soil near a hot water spring at Nelumwewa, Polonnaruwa District, Sri Lanka, by enrichment for growth at high temperature $\left(\sim 60^{\circ} \mathrm{C}\right)$. The isolated bacterium was characterized morphologically and biochemically (Grams reaction and catalase test). Molecular identification was based on 16s RNA gene sequencing (using 27F and 534R universal primer pair). The 16s rRNA analysis and biochemical characteristics of bacteria were compared to confirm the bacterial species as Bacillus licheniformis strain NWMF1

\section{Cloning of B. licheniformis DNA polymerase-1 gene}

Multiple sequence alignment of open reading frames (ORF) of B. licheniformis strain NWMF1, DNAP-1 genes were carried out to identify conserved sequences for designing of the PCR primers. NcoI and BamHI restriction enzyme recognition sequences were added to the 3' region of the forward and reverse primers respectively. Further, the His-tag purification sequence $(\mathrm{CAC})_{6}$ was added to the reverse primer. The Ompa (Outer Membrane Protein-A) signal sequence was added to the forward primer. The forward primer, DNAP-1F (5'GCA TGA CCA TG GGT ATG AAA AAG ACA GCT ATC GCG ATT GCA GTG GCA CTG GCT GGT TTC GCT ACC GTT GCG CAA GCT ATG ACT GAA AAA AAA TTA GTA TT-3') and the reverse primer DNAP-1R (5'-GCA TGA GGA TCC CTA CAC CACCACCACCACCAC TTT TGC ATC GTA CCA TGAA-3') were custom-synthesized.

Bacterial genomic DNA was isolated according to the method of Dubnau (1982). The isolated B. licheniformis strain NWMF1 was PCR- amplified from genomic DNA, gel-purified and cloned into PGEM $^{\mathrm{R}}$-T easy vector (Promega) and transformed into E.coli JM109 high efficiency competent cells. Recombinant plasmid DNA was isolated and confirmed by sequencing.

The recombinant plasmid was digested with $\mathrm{Ncol}$ and BamHI restriction enzymes to remove the cloned the DNAP-1 gene and subsequently gel-purified. It was then cloned into the Ncol/BamHI site of pET $28 \mathrm{a}+$ expression vector and 
transformed into E. coli BL-21(DE3)pLysS high efficient competent cells, compatible with kanamycin selection. Selected recombinants were screened by colony PCR and confirmed by sequence analysis as previously stated Additionally, Interpro (EMBL-EBI) protein analyses were performed to detect conserved domains in the translated protein sequence. Structural and functional features of the protein were obtained from Predictprotein online prediction tool, UniProt protein database and Protein Data Bank (PDB).

\section{Purification and analysis of expressed recombinant DNAP-1 protein}

Extracellular DNA Polymerase-I production from recombinant E. coli BL21(DE3)pLysS cells were induced by IPTG. The supernatant of the LB broth was separated and over expressed DNA Polymerase-l were purified by using MagneHis protein purification system (Promega, USA) according to the manufacturer's instructions.

The activity of recombinant, purified DNAP-1 was demonstrated by using a modified protocol of a previously optimized 30-cycle PCR program to amplify the alkaline protease gene from B. licheniformis (Wanigasekara et al., 2016). In this protocol, the extension step was carried out at $62^{\circ} \mathrm{C}$ and $1 \mu$ l of enzyme (out of a total of $60 \mu \mathrm{l}$ of His-tag purified enzyme extract) was added in each cycle at the primer annealing step, in order to accommodate the moderate thermostability of the recombinant DNAP-1.

Protein concentration was measured by the bicinchoninic acid assay (Smith $\boldsymbol{e}$ al., 1985) with BSA as the standard. Protein samples were prepared for SDSPAGE as described in Tang $\boldsymbol{e t}$ al., (2001) and analyzed according to the method of Laemmli (1970).

\section{RESULTS AND DISCUSSION}

The selected bacterium showed optimum growth at $55^{\circ} \mathrm{C}$. The Gram positive, motile, catalase positive, spore forming, rod shaped bacterium was identified as Bacillus licheniformis and the strain was designated as NWMF-1

The PCR amplified DNAP-1 gene from B. licheniformis NWMF-1 was observed between $2500 \mathrm{bp}$ and $3000 \mathrm{bp}$ (Figure 1).

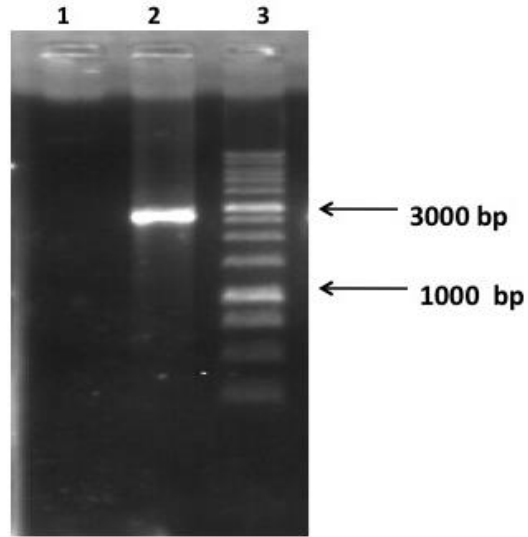

Figure 1 Gel electrophoresis photographs of PCR amplified DNAP-1 gene from Bacillus licheniformis strain NWMF1. Lane 1: Negative control, Lane 2: PCR amplified DNAP-1 gene, Lane 3: 1kb DNA ladder (Promega).

Sequence analysis revealed that the complete coding sequence was $2640 \mathrm{bp}$. The sequence has been submitted to the NCBI data base and is available under the accession number: MF536412.1. Nucleotide BLAST (NCBI) of the complete nucleotide sequence obtained for $B$. licheniformis NWMF-1 DNAP-1 gene showed 99\% identity with DNA polymerase-l gene from B. licheniformis DSM13 $=$ ATCC $14580(\underline{\mathrm{AE} 017333.1})$ and B. licheniformis BL1202 (P017247.1).

PCR-amplification of the alkaline protease gene $(1140 \mathrm{bp})$ from B. licheniformis (NCBI data base accession number: MF496035.1) using His-tag purified recombinant DNAP-1 revealed a DNA fragment of expected size during electrophoresis on a $0.8 \%$ agarose gel. This indicated that the recombinant DNAP-1 enzyme was active (Figure 2).

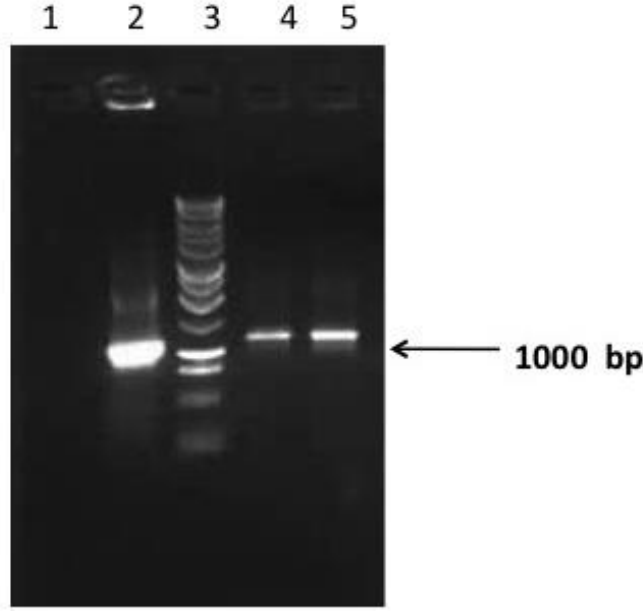

Figure 2 Gel photograph of PCR-amplified alkaline protease gene using recombinant DNAP-1 enzyme. Lane 1: negative control (No enzyme), Lane 2: positive control (amplified using GoTaq polymerase), Lane 3: 1kb ladder, Lanes 4 and 5: amplified products using recombinant DNAP-1 enzyme.

SDS-PAGE of His-tag purified recombinant DNAP-1 revealed a single protein band between $75-100 \mathrm{kDa}$ (Figure 3 ). The size of the protein was approximately $92 \mathrm{KDa}$, as obtained by the EXPASy - ProtParam tool.

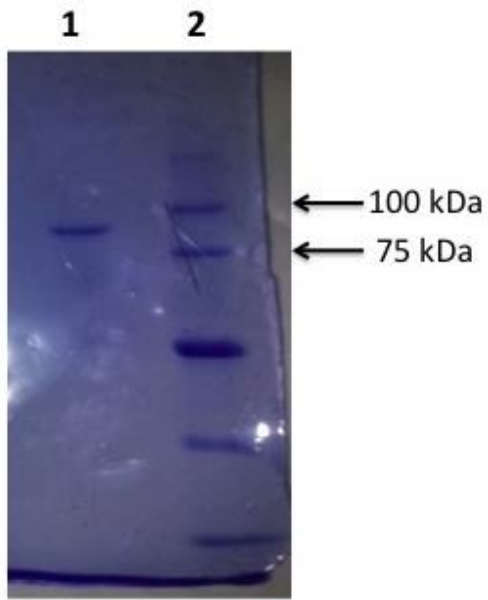

Figure 3 SDS PAGE gel photograph for His-tag purified DNAP-1. Lane 1: DNAP-1. Lane 2: Broad ranged protein ladder.

The complete amino acid sequence obtained for $B$. licheniformis NWMF-1 DNAP-1 consisted of 879 amino acids and it showed $100 \%$ identity with Bacillus licheniformis strain NWMF1 DNA polymerase-I protein sequences from UniProt (EMBL-EBI).

Structural features of the DNAP-1 was obtained using ProteinPredict online too (Yachdavet al, 2014). The active site of the mature peptide contains 24 amino acid residues (aspartic acid; positions 11, 61, 112, 113, 136, 138, 833, histidine; positions 685, 832, serine; position 620, threonine; positions $614,616,793$ glutamate; position 110, arginine; position $618,705,792$, glutamine; position 615 , 800, leucine; position 619, valine; position 831, lysine; position 709 , tyrosine; position 717 and asparagine; position 796). The conserved 5' to 3 exonuclease domain (PIN_53EXO) of family A DNA polymerases was also observed in B.licheniformis NWMF-1 DNAP-1. The predicted secondary structure consists of $36.2 \%$ loop, $55.4 \%$ helix and $8.4 \%$ strand (Rost et al, 2004) The predicted protein contains a single disulphide bond.

\section{CONCLUSION}

A moderately thermostable bacterium isolated from soil near a hot water spring was identified as Bacillus licheniformis. The strain was designated as NWMF-1. The DNA polymerase-| gene from Bacillus licheniformis strain NWMF1 was over expressed in an E. coli expression system. The His-tag purified DNAP-1 showed polymerase activity while carrying the histidine tag and is expected to improve when the tag is cleaved. The cloned DNAP-1 has potential for application in loop mediated isothermal amplification (LAMP) and other molecular biology techniques, especially in developing countries.

Acknowledgments: MSc vote Department of Biochemistry and Molecular Biology, Faculty of medicine, University of Colombo. 


\section{REFERENCES}

CURTIS, K. A., DONNA, L. R., OWEN, S. M. 2008. Rapid Detection of HIV-1 by Reverse-Transcription, Loop-Mediated Isothermal Amplification (RTLAMP). Journal of Virological Methods, 151(2), http://dx.doi.org/10.1016/j.jviromet.2008.04.011

DUBNAU, D. A. 1982. Genetic Transformation in Bacillus Subtilisin." In: Dabau D. A, Ed. The Molecular Biology of the Bacilli. New York: Academic press. $\quad$ http://www.worldcat.org/title/molecular-biology-of-thebacilli/oclc/559694668

ISHINO, S., YOSHIZUMI, I. 2014. DNA Polymerases as Useful Reagents for Biotechnology - the History of Developmental Research in the Field. Frontiers in microbiology, 5(29), pp. 1-8. http://dx.doi.org/10.3389/fmicb.2014.00465 LAEMMLI, U. K. 1970. Cleavage of Structural Proteins During the Assembly of the Head of Bacteriophage T4. Nature, 227, 680-685. http://dx.doi.org/10.1038/227680a0

MORI, Y., HIDETOSHI, K., TSUGUNORI, N. 2013. Loop-Mediated Isothermal Amplification (LAMP): Recent Progress in Research and Development. Journal of Infection and Chemotherapy, 19(3), 404-11. http://dx.doi.org/10.1007/s10156-013-0590-0

ROST, B., YACHDAV, G., LIU, J. 2004. The Predict Protein Server. Nucleic Acids Research 32, 321-26. http://dx.doi.org/10.1093/nar/gkh377

SAMBROOK, J. 2012. Molecular Cloning A LABORATORY MANUAL. 4th ed Edited by M R Green. Molecular cloning: A laboratory manual / J. Sambrook, E.F. Fritsch, T. Maniatis - details. New York: Cold Spring Harbor Laboratory Press. http://trove.nla.gov.au/work/13615226

SATTABONGKOT, JETSUMON, TAKAFUMI, T., EUN-TAEK, H., SIRASATE, B. 2014. Loop-Mediated Isothermal Amplification Assay for Rapid Diagnosis of Malaria Infections in an Area of Endemicity in Thailand. Journal of Clinical Microbiology, 52(5), 1471-77. http://dx.doi.org/10.1128/JCM.0331313

SMITH, P. K., KROHN, I.R., HERMANSON, T. G., MALLIA, K. A. 1985 Measurement of Protein Using Bicinchoninic Acid. Anal. Biochem, 150, 76-85. http://dx.doi.org/10.1016/0003-2697(85)90442-7

TANG, X. M., SHAO, W. L., ZHUGE, J. 2001. Cloning and Expression of the Gene Encoding Alkaline Protease from Bacillus licheniformis 16816 in E.Coli. Chinese J. Biotech, 11,3-6 http://dx.doi.org/10.1023/B:BILE.0000030042.91094.38

WANIGASEKARA, W. M. J. M. B., JAYASENA, S. M. T., WITHARANA, A W. C. P., MATHEW, C. P. D. W., WIJESUNDERA, W. S. S. 2016. Cloning of Alkaline Protease Gene from Thermophilic Bacillus licheniformis into an E.Coli Expression System.(Proceding of the work of the $3^{\text {rd }}$ Edition of the Young Researchers in Biosciences International Symposium) Cluj-Napoca: Romania, 54.

https://www.researchgate.net/publication/312492199_Cloning_of_DNA_poly merase gene from thermophilic Bacillus licheniformis into an Ecoli exp ression system

YACHDAV, G., KLOPPMANN, E., KAJAN, L., HECHT, M., GOLDBERG, T. HAMP, T., HONIGSCHMID, P. 2014. PredictProtein--an Open Resource for Online Prediction of Protein Structural and Functional Features. Nucleic Acids Research, 42(1), 337-43. http://dx.doi.org/10.1093/nar/gku366 